\title{
Impact of body composition on outcome in patients with early breast cancer
}

\author{
Elise Deluche $^{1} \cdot$ Sophie Leobon ${ }^{1} \cdot$ Jean Claude Desport ${ }^{2} \cdot$ Laurence Venat-Bouvet $^{1}$ • \\ Julie Usseglio $^{1} \cdot$ Nicole Tubiana-Mathieu ${ }^{1}$
}

Received: 4 April 2017 / Accepted: 13 September 2017 /Published online: 25 September 2017

(C) The Author(s) 2017. This article is an open access publication

\begin{abstract}
Purpose We investigated the impact of body composition on outcomes of patients with early breast cancer. Skeletal muscle mass, visceral adipose tissue (VAT), subcutaneous adipose tissue (SAT), and muscle fat infiltration or inter-muscular adipose tissue areas (IMAT), obtained by computed tomography (CT), were assessed.

Methods A total of 119 female patients who had breast cancer were included in this retrospective study. The total skeletal muscle and fat tissue areas were evaluated in two adjacent axial slices obtained at the third lumbar vertebra by CT used for disease staging. The women were assigned to either a sarcopenia or non-sarcopenia group based on their skeletal muscle index (cut-off $41.0 \mathrm{~cm}^{2} / \mathrm{m}^{2}$ ). They also were classified into high and low VAT/SAT ratio groups and assigned to either the high or low IMAT index group. The association of the body composition parameters and prognosis was statistically analyzed.

Results Among the 119 evaluable patients, 58 were sarcopenic (48.8\%), 55 (46.2\%) had a high VAT/SAT ratio, and $62(52.1 \%)$ had a high IMAT index. Median follow-up was 52.4 months. Multivariate analysis revealed sarcopenia and IMAT index as independent prognostic factors for disease-free survival ( $p=0.02$ and $p=0.04$, respectively) and overall survival ( $p=0.05$ and $p=0.02$, respectively). BMI was not significantly associated with disease-free survival, but a trend was observed $(p=0.09)$.
\end{abstract}

Elise Deluche

elise.deluche@chu-limoges.fr

1 Department of Medical Oncology, University Hospital, 2 Avenue Martin Luther King, 87042 Limoges Cedex, France

2 Nutrition Unit, University Hospital, 87042 Limoges, France
Conclusions Sarcopenia and IMAT index are independent prognostic factors in early breast cancer; therefore, assessing body composition could be a simple and useful approach to integrate into patient management.

Keywords Early breast cancer $\cdot$ Prognosis $\cdot$ Sarcopenia $\cdot$ Body composition

\section{Introduction}

Breast cancer is the most frequent cancer in women and one of the most common causes of cancer-related death among women in the world [1]. In addition to traditional prognostic factors (e.g., tumor size, lymph node status, tumor histology), new clinical or biological markers are the goal of ongoing searches to improve management of this disease.

Body composition seems to be a factor of interest in oncology and refers to the amount and distribution of lean tissue and adipose tissue in the human body. Different parameters can be evaluated to assess body composition, but the best-known parameter is body mass index (BMI), defined as weight/ height ${ }^{2}\left(\mathrm{~kg} / \mathrm{m}^{2}\right)$ [2]. It has been commonly used to assess nutritional status in cancer, but the role of this anthropometric tool in breast cancer is unclear. Some studies have shown that overweight and obesity are strong risk factors for breast cancer [3], and they are described as prognostic factors for disease recurrence and shorter overall survival (OS) compared to normal-weight patients [4-6]; however, other studies have not confirmed the prognostic role of BMI in breast cancer [7-9].

BMI thus seems insufficient on its own. For example, sarcopenic obesity refers to obese cancer patients who lose muscle mass but for whom the weight loss may be masked by excess fat mass if BMI is considered on its own [10]. Other 
parameters that are more representative of body composition have been highlighted thanks to the development of image analysis methods such as computed tomography (CT) scans [11]. Among the compartments that can be distinguished on CT, skeletal muscle mass (SMM), visceral adipose tissue (VAT), subcutaneous adipose tissue (SAT), and muscle fat infiltration or inter-muscular adipose tissue areas (IMAT) have been analyzed [12].

Body composition is an important feature because it affects the efficacy and toxicity of chemotherapy in different cancers $[13,14]$ and is associated with patient outcomes $[15,16]$. In breast cancer [17], some studies have analyzed the association between body composition and outcomes or toxicities in various situations [18-21].

The objective of this work was to investigate the impact of body composition on outcomes in patients with early breast cancer for whom a CT scan was performed because of aggressive clinico-pathological characteristics.

\section{Material and methods}

\section{Patients}

This retrospective study was performed at Limoges University Hospital on patients treated from March 2007 to June 2016. They were selected from the institution's database according to all following criteria: (1) Patients had early breast cancer for which a CT scan was performed for staging because of aggressive clinico-pathological characteristics; (2) CT scan imaging was performed in the hospital before the beginning of chemotherapy and images were saved in the institution's radiology database; (3) clinico-pathological data, including age, menopausal status, anthropometric measures, tumor characteristics, and treatment, had to be available and were extracted from the medical records and electronic database. Patients whose breast cancer was diagnosed as metastatic were excluded.

Clinical data were collected in accordance with French bioethics laws regarding patient information and consent. Patients also sign informed consent for use of data from biological samples and collections at the beginning of their medical care. The use of retrospective and prospective data from the BRTS "Regional solid tumors base" was validated by the ethics committee.

\section{Anthropometric measures}

Weight and height were recorded according to standard methods at the first appointment. Weight was measured by a nurse using the same portable digital scale (Tanita, Tokyo, Japan). Only the first weight was considered for the study. Nurses also measured height using a stadiometer $( \pm 0.5 \mathrm{~cm})$. BMI was calculated and the median BMI was used for the study. Because of the small sample size, BMI was dichotomized as $<25 \mathrm{~kg} / \mathrm{m}^{2}$ (underweight or normal) and $\geq 25 \mathrm{~kg} / \mathrm{m}^{2}$ (overweight or obese), as in other studies [13, 22].

\section{CT scan imaging}

CT scans were performed in patients with aggressive clinicopathological factors prior to the beginning of chemotherapy and according to French recommendations [23].

With standard operating procedures [24], SMM, VAT, SAT, and IMAT were assessed using the average of measurements on two adjacent axial slices at the third lumbar vertebra (L3) (Fig. 1). To evaluate SMM, the following parameters were analyzed: the masses of the psoas, quadratus lumborum, transversus abdominis, external and internal obliques, rectus abdominis, and erector spinae muscles. The fat present in the psoas was not taken into account for VAT and defining IMAT.

The measured total cross-section $\left(\mathrm{cm}^{2}\right)$ was normalized for meters squared $\left(\mathrm{m}^{2}\right)$, expressed in units of $\mathrm{cm}^{2} / \mathrm{m}^{2}$, and reported respectively as the SMM, VAT, SAT, and IMAT indexes. Images were analyzed using Slice-O-Matic software (v. 4.3 Tomovision, Montreal, Canada).

Because of the lack of consensus, we defined cut-offs as previously reported:

- L3 skeletal muscle index $<41.0 \mathrm{~cm}^{2} / \mathrm{m}^{2}$ defined sarcopenia $[15-17,25]$;

- the cut-off points for the VAT, SAT, and the IMAT indexes were based on the median [26]; and

- VAT/SAT ratio was calculated for each patient, and we divided patients according to the 50th percentiles of the VAT/SAT ratio [27].

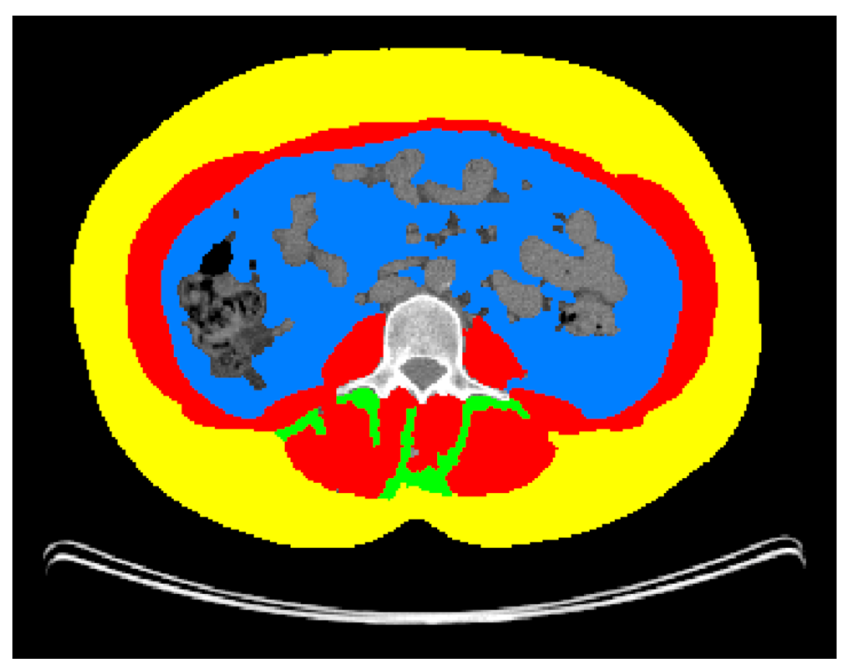

Fig. 1 Axial CT image of the third lumbar vertebral region with corresponding highlighted body composition in patients: skeletal muscle mass (SMM) in red, visceral (VAT) in blue, subcutaneous (SAT) fat tissues in yellow, and muscle fat infiltration (IMAT) in green 


\section{Statistical analysis}

All data were collected and analyzed using STATVIEW@ software (SAS Institute, Inc., Cary, NC, USA). Quantitative results were given as median $\pm \mathrm{SD}$ and qualitative results as percentages. The significance of the difference in the variables among the groups was calculated using the chi-square test. Medians were compared with the nonparametric MannWhitney $U$ test for ordinal variables. Overall survival (OS) was calculated from the date of diagnosis to the date of death from any cause or the date of last follow-up. Disease-free survival (DFS) in months was calculated from the date of diagnosis until disease progression or relapse. Survival curves were obtained using the Kaplan-Meier technique. Relevant variables associated with OS and DFS were examined using univariable and, where applicable, multivariable Cox proportional hazards regression. For the multivariable models, a univariable inclusion criterion of $p \leq 0.2$ was used. All statistical tests had a level of significance established at $p<0.05$.

\section{Results}

\section{Clinico-pathological characteristics}

A total of 119 patients for whom all inclusion criteria were gathered were included in this study. Clinico-pathological data are presented in Table 1 . The median age was 56.0 years (range 21-87 years). Patient characteristics were analyzed according to body composition parameters: sarcopenia (SMM $<41.0 \mathrm{~cm}^{2} / \mathrm{m}^{2}$ ), VAT/SAT ratio, and IMAT. Of the 119 evaluable patients, 58 were sarcopenic $(48.8 \%)$ and 61 were non-sarcopenic $(51.2 \%)$ without any significant differences in clinico-pathological characteristics between the two populations.

Fifty-five patients (46.2\%) had a high VAT/SAT ratio, and 64 patients (53.8\%) had a low VAT/SAT ratio. The difference in clinico-pathological characteristics was the age and the menopausal status: patients with a high VAT/SAT ratio were older $(p<0.0001)$ and more often postmenopausal $(p<0.0001)$.

Sixty-two patients $(52.1 \%)$ had a high IMAT index and 57 patients $(47.9 \%)$ a low IMAT index. Patients with a high IMAT index were older $(p<0.0001)$ and had more tumors with lymph node involvement $(p=0.01)$.

\section{Anthropometric results}

Anthropometric results are shown in Table 2.

Patients with sarcopenia compared to patients without sarcopenia had lower BMI $(p<0.0001)$, SMM index $(p<0.0001)$, and especially lower SAT $(p<0.0001)$ and VAT $(p=0.002)$ indexes. The IMAT index was higher in the sarcopenia group ( $p=0.04)$; however, VAT/SAT ratio was similar in the two groups $(p=0.5)$.

The median SAT was $85.9 \pm 3.3 \mathrm{~cm}^{2} / \mathrm{m}^{2}$, and the median VAT was $41.1 \pm 2.2 \mathrm{~cm}^{2} / \mathrm{m}^{2}$. In the group with a low VAT/SAT ratio compared to the group with a high VAT/SAT ratio, the SAT index was similar but VAT index was higher $(p<0.0001)$. BMI and SMM index were independent of VAT/SAT ratio, and the IMAT index was higher in the group with a high VAT/SAT ratio $(p=0.002)$.

The median IMAT index was $3.5 \pm 0.2 \mathrm{~cm} 2 / \mathrm{m} 2$. A high IMAT index was associated with a high VAT index $(p=0.008)$, a high VAT/SAT ratio $(p=0.03)$, and sarcopenia $(p=0.03)$ whereas BMI and the SAT index were similar.

\section{Obese patient characteristics according to sarcopenia}

Among the 119 patients studied, 70 patients were with an excess of weight (BMI $\geq 25 \mathrm{~kg} / \mathrm{m} 2$ ). According to the predefined cut-off values, 22 patients were considered with sarcopenia. Obese/overweight patients with sarcopenia were older $(p=0.01)$ and more postmenopausal $(p=0.009)$. BMI was higher in this group $(p=0.02)$ as SAT index $(p=0.04)$.

The other parameters were comparable between sarcopenic-obese/overweight patients and patients without sarcopenia.

Considering body composition parameters, no sarcopenia and IMAT index $<4.4 \mathrm{~cm} 2 / \mathrm{m} 2$ were significantly associated with better PFS and OS in univariate analysis. On multivariate analysis, only sarcopenia was found to be independently associated with poor PFS (hazard ratio (HR) 0.3. Confidence interval (CI) $0.1-0.9 ; p=0.03$ ).

\section{Anthropometric parameters and outcomes}

The results of the univariate and multivariate analyses of DFS and OS are shown in Table 3. Median follow-up was $52.4(2.0-108.4)$ months.

\section{Disease-free survival}

The median DFS was $17.5(2.0-49.4)$ months. There were 25 relapses (21\%) with 9 local relapses and 22 metastases. In the univariate analysis, sarcopenia, BMI, VAT index, IMAT index, and VAT/SAT ratio were associated with DFS and were thus included in the multivariate model. In the multivariate analysis, only two factors were significantly associated with DFS: sarcopenia and IMAT index. No sarcopenia was significantly associated with better DFS (HR $0.3 ; 95 \%$ CI $0.1-0.8$; $p=0.02$ ) and IMAT index $>3.5 \mathrm{~cm}^{2} / \mathrm{m}^{2}$ with worse DFS (HR $2.8 ; 95 \%$ CI $1.0-7.8 ; p=0.04)$. BMI was not significantly associated with DFS, but we observed a trend towards significance $(p=0.09)$ (Fig. 2). BMI is not expressed in Fig. 2. 


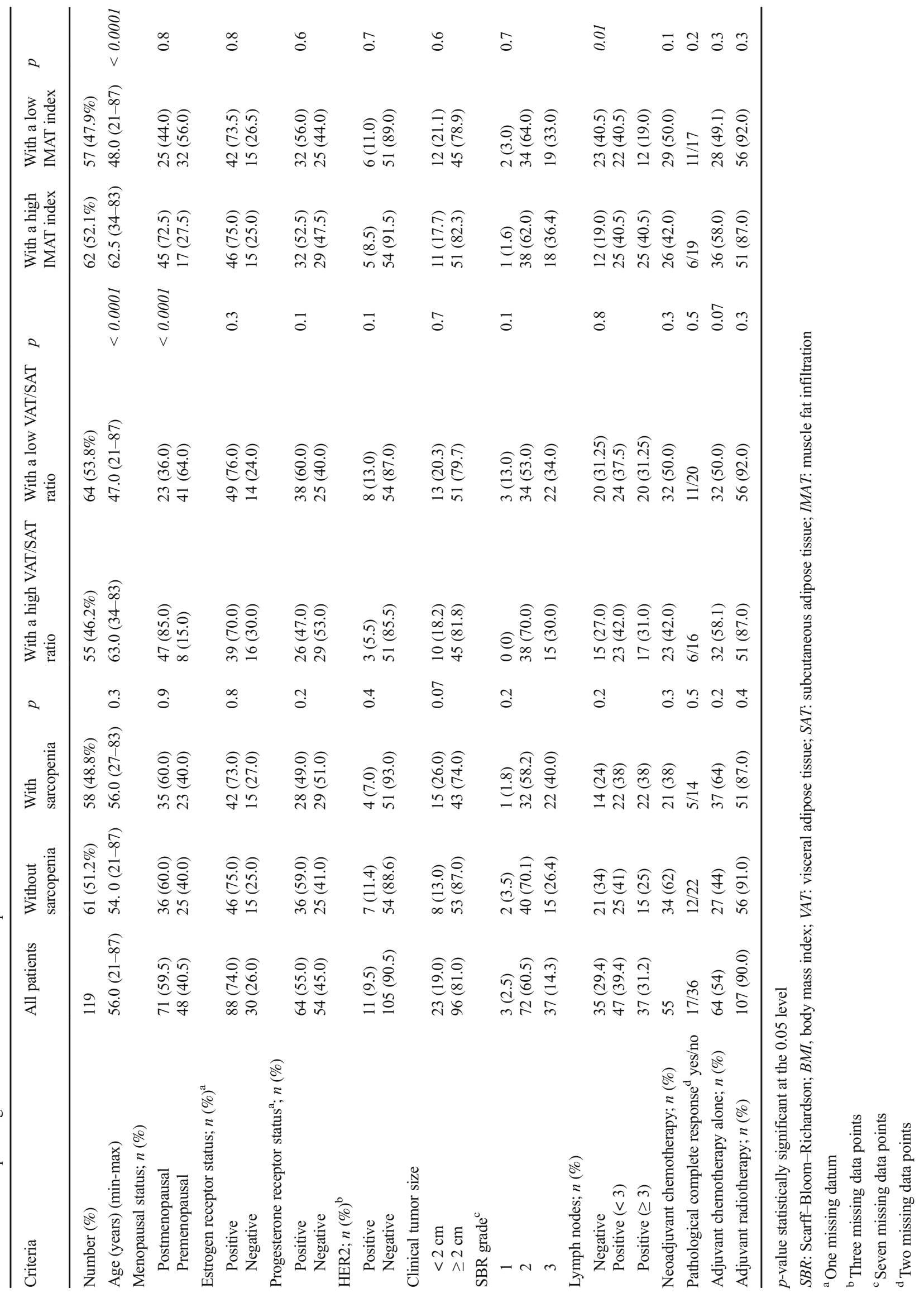


Overall survival

The median OS was 52.4 (2.0-108.4) months with 22 deaths (18.4\%). Among the body composition parameters, sarcopenia, IMAT index, and VAT/SAT ratio were associated with OS in the univariate analysis. In the multivariate analysis, only two parameters were significantly associated with worse OS: no sarcopenia (HR $0.3 ; 95 \%$ CI $0.1-0.99 ; p=0.05$ ) and IMAT index $>3.5 \mathrm{~cm}^{2} / \mathrm{m}^{2}$ (HR 3.6; 95\% CI 1.2-10.8; $p=0.02$ ) (Fig. 2). BMI is not expressed in Fig. 2.

\section{Discussion}

Our study highlighted two parameters of the body composition, sarcopenia and the IMAT index, are significantly associated with DFS and OS in patients with breast cancer. Patients with sarcopenia and a high IMAT index $\left(>3.5 \mathrm{~cm}^{2} / \mathrm{m}^{2}\right)$ had a poor prognosis.

Among body composition features, sarcopenia has emerged as a common parameter in many cancers [25]. To our knowledge, only one study has determined the prevalence of sarcopenia in adjuvant breast cancer [19]; Villaseñor et al. found that $15.9 \%$ of sarcopenic patients $(n=471)$ had been diagnosed with stage I-IIIA breast cancer. We found a higher prevalence of sarcopenia (47.8\%), probably because of the imaging method used for sarcopenia evaluation; Villaseñor et al. used dual X-ray absorptiometry scans whereas we used CT scans. Both methods were validated, but a CT scan allows for more accurate evaluation of sarcopenia [28]. Moreover, measurement of body composition using CT scans is easier and more reproducible, as previously reported [17, 29].

In addition, we found that sarcopenia was an independent factor in poor DFS and OS, as in other studies focusing on breast [19] and other cancers [17]. Villaseñor et al. reported that sarcopenia $\left(<5.45 \mathrm{~kg} / \mathrm{m}^{2}\right)$ was associated with an increased risk of overall mortality in adjuvant breast cancer survivors (HR 2.86; 95\% CI 1.67-4.89), but breast cancerspecific mortality was not statistically increased (HR 1.95; 95\% CI 0.87-4.35).

In the neoadjuvant breast cancer setting, sarcopenia has been associated with OS but not with DFS [18], and Iwase et al. reported that the distant DFS (DDFS) did not differ significantly between the two groups [21]. The main difficulty in the study of sarcopenia is an assortment of definitions with a variety of cut-offs. A European working group on sarcopenia recommends incorporating both muscle mass and muscle function into the definition of sarcopenia [30]. Our study was retrospective, so it was not possible to evaluate muscle function (strength or performance) to define sarcopenia, which was defined only by CT scan, as is commonly accepted [17]. 
Table 3 Univariate and multivariate analyses of body composition parameters for DFS and OS ( $\mathrm{n}=119)$

\begin{tabular}{|c|c|c|c|c|c|c|c|c|}
\hline & \multicolumn{4}{|c|}{ Disease-free survival } & \multicolumn{4}{|l|}{ Overall survival } \\
\hline & \multicolumn{2}{|l|}{ Univariate } & \multicolumn{2}{|l|}{ Multivariate } & \multicolumn{2}{|l|}{ Univariate } & \multicolumn{2}{|l|}{ Multivariate } \\
\hline & $\mathrm{HR}(95 \% \mathrm{CI})$ & $p$ & $\mathrm{HR}(95 \% \mathrm{CI})$ & $p$ & $\mathrm{HR}(95 \% \mathrm{CI})$ & $p$ & $\mathrm{HR}(95 \% \mathrm{CI})$ & $p$ \\
\hline Sarcopenia: yes vs. no & $0.4(0.2-1.1)$ & 0.08 & $0.3(0.1-0.8)$ & 0.02 & $0.3(0.09-0.8)$ & 0.03 & $0.3(0.1-0.99)$ & 0.05 \\
\hline $\mathrm{BMI}<25 \mathrm{~kg} / \mathrm{m}^{2}$ vs. $>25 \mathrm{~kg} / \mathrm{m}^{2}$ & $0.4(0.1-1.0)$ & 0.05 & $2.8(0.1-1.1)$ & 0.09 & $0.7(0.3-1.7)$ & 0.4 & & \\
\hline $\begin{array}{l}\text { SAT index }\left(\mathrm{cm}^{2} / \mathrm{m}^{2}\right) \\
<107.7 \mathrm{~cm}^{2} / \mathrm{m}^{2} \text { vs. }>107.7 \mathrm{~cm}^{2} / \mathrm{m}^{2}\end{array}$ & $0.5(0.2-1.1)$ & 0.1 & $0.5(0.1-1.3)$ & 0.1 & $0.9(0.3-2.3)$ & 0.8 & & \\
\hline $\begin{array}{l}\text { VAT index }\left(\mathrm{cm}^{2} / \mathrm{m}^{2}\right) \\
<55.6 \mathrm{~cm}^{2} / \mathrm{m}^{2} \mathrm{vs} .>55.6 \mathrm{~cm}^{2} / \mathrm{m}^{2}\end{array}$ & $0.4(0.2-1.0)$ & 0.05 & $1.4(0.5-4.1)$ & 0.5 & $0.6(0.2-1.6)$ & 0.3 & & \\
\hline $\begin{array}{l}\text { IMAT index }\left(\mathrm{cm}^{2} / \mathrm{m}^{2}\right) \\
<3.5 \mathrm{~cm}^{2} / \mathrm{m}^{2} \text { vs. }>3.5 \mathrm{~cm}^{2} / \mathrm{m}^{2}\end{array}$ & $4.0(1.5-10.6)$ & 0.005 & $2.8(1.0-7.8)$ & 0.04 & $4.0(1.3-12.1)$ & 0.01 & $3.6(1.2-10.8)$ & 0.02 \\
\hline $\begin{array}{l}\text { VAT/SAT ratio } \\
<0.69 \mathrm{~cm}^{2} / \mathrm{m}^{2} \text { vs. }>0.69 \mathrm{~cm}^{2} / \mathrm{m}^{2}\end{array}$ & $2.5(1.0-5.9)$ & 0.03 & $2.0(0.7-5.6)$ & 0.1 & $2.2(0.9-5.6)$ & 0.07 & $1.5(0.6-3.9)$ & 0.3 \\
\hline
\end{tabular}

BMI: body mass index; VAT index: visceral adipose tissue; SAT index: subcutaneous adipose tissue; IMAT index: muscle fat infiltration
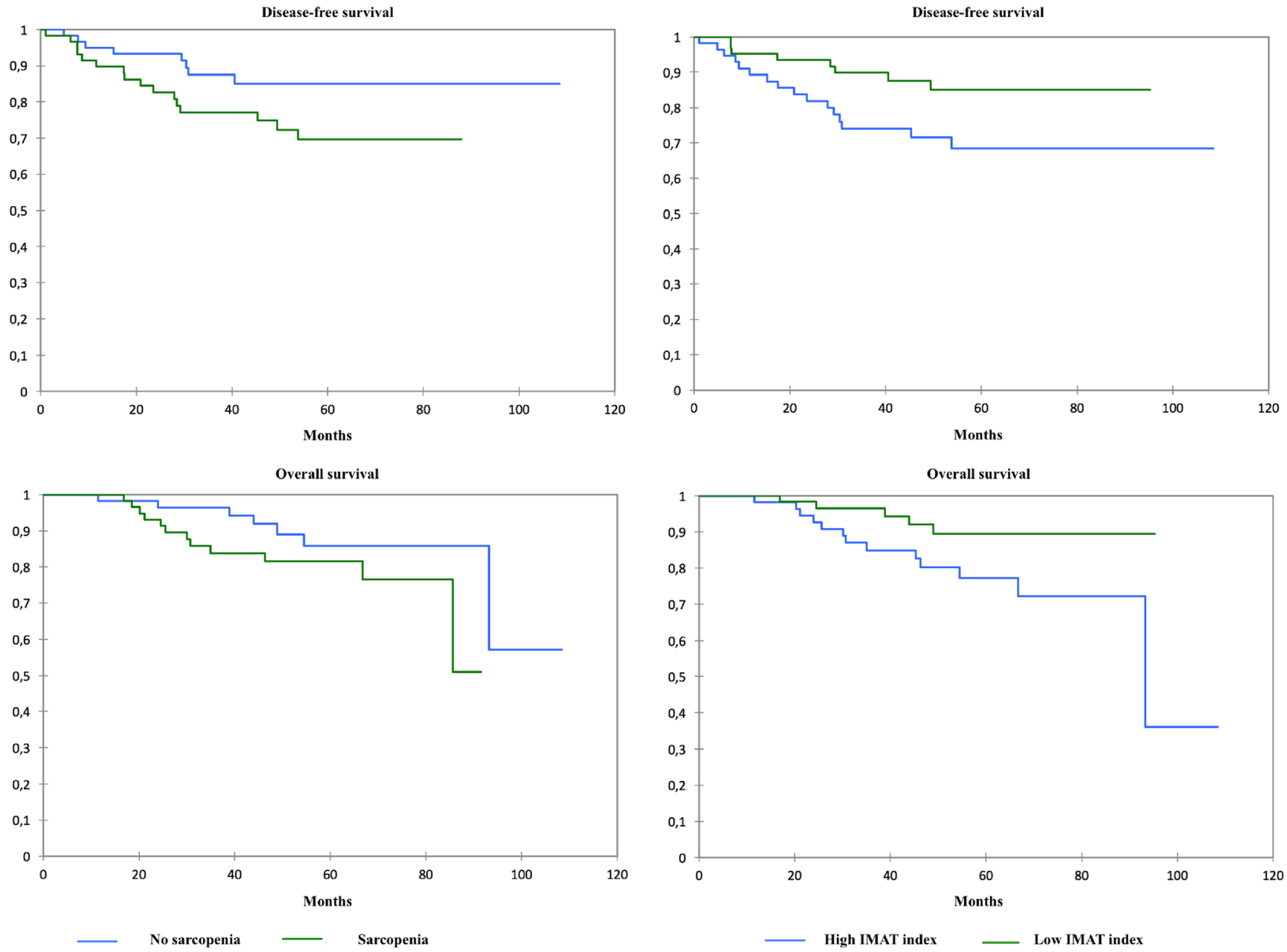

Fig. 2 Disease-free survival and overall survival of patients with breast cancer based on skeletal muscle mass index (or sarcopenia) and muscle fat infiltration (IMAT) index $(n=119)$ 
In our study, the threshold value for sarcopenia was near that of Fabbro et al. $\left(41.0 \mathrm{~cm}^{2} / \mathrm{m}^{2}\right.$ in the current work vs. $38.5 \mathrm{~cm}^{2} / \mathrm{m}^{2}$ ) [17]. There is no gold standard for defining the optimal cut-off of sarcopenia in breast cancer, so we relied on prospective data and meta-analyses in different cancers. The cut-off predominantly found was fixed at $41.0 \mathrm{~cm}^{2} / \mathrm{m}^{2}$ [15-17, 25].

The effect of the combination of sarcopenia and obesity (sarcopenic obesity) has been examined in different cancers, suggesting that sarcopenia is an independent prognostic factor of lower survival in obese patients with cancer as we showed despite our small population [3-6]. Prado et al. reported that in patients ( $n=250$ ) with gastrointestinal cancer or lung cancer, obese patients with sarcopenia had an increased risk of mortality (HR 4.2; 95\% CI 2.4-7.2) compared to obese nonsarcopenic patients [15]. In pancreatic cancer, Tan et al. reported that sarcopenia was an independent predictor of mortality among overweight/obese patients $(n=111)$ (HR02.07; 95\% CI, 1.23-3.50) [13].

At least, different studies show that maintaining physical exercise has positive effects and decreases sarcopenia especially in elderly patients $[31,32]$. The fight against sarcopenia thus requires an effective screening but also by the implementation of physical activity.

We found IMAT as an independent prognosis factor of survival in breast cancer patients. We evaluated IMAT separately from other parameters, as did van Dijk et al. [33]. A recent study reported that high inter-muscular adipose tissue content was predictive of an unfavorable prognosis in hepatocellular carcinoma [34], but to our knowledge, the current work is the first to report a relationship between IMAT and outcomes in breast cancer.

The other parameters we examined (BMI and VAT/SAT ratio) were not associated with outcomes. The median values of VAT and SAT were taken into account because they were previously implicated as prognostic in metastatic colorectal cancer [26]. To our knowledge, only one study has evaluated the relation among VAT, SAT, and outcomes in advanced breast cancer [21]. In that study conducted in 172 patients with breast cancer treated in a neoadjuvant setting, the DDFS was significantly worse for the high VAT group (VAT $\geq 100 \mathrm{~cm}^{2}$ ), but high SAT $\left(\right.$ SAT $\geq 100 \mathrm{~cm}^{2}$ ) was not associated with DDFS and OS. These thresholds were based on the guideline for screening metabolic disease created by the Japan Society for the Study of Obesity [35]. In other cancers, the impact of VAT and SAT remains unclear, and the variation in cut-offs can explain the difference among all studies [36]. Moreover, there are differences between the two groups considering the menopausal status. It is indicated that menopause causes changes in body composition with increased visceral fat composition as Iwase et al. showed [1]. The authors reported that subcutaneous fat area and visceral fat area increased significantly and skeletal muscle area decreased significantly after menopause (all $p<0.05$ ).
The limitations of our study are its retrospective nature and the relatively small number of patients. According to recommendations, CT scans are not systematically used to assess extension in breast cancer. In order to study specifically body composition, instead of including all patients with early breast cancer, we selected patients who had an initial CT assessment and were probably more severe. Finally, our multivariate analysis included only body composition criteria.

\section{Conclusion}

Our results suggest that the evaluation of body composition, especially sarcopenia and IMAT index based on CT scan analysis, is worth including in breast cancer management. We propose a prospective study integrating CT imaging and functional tests to validate the prognostic role of the two parameters in early breast cancer in a larger population of patients.

Compliance with ethical standards Clinical data were collected in accordance with the French bioethics laws regarding patient information and consent.

Conflict of interest The authors declare that there are no conflicts of interest.

Open Access This article is distributed under the terms of the Creative Commons Attribution-NonCommercial 4.0 International License (http:// creativecommons.org/licenses/by-nc/4.0/), which permits any noncommercial use, distribution, and reproduction in any medium, provided you give appropriate credit to the original author(s) and the source, provide a link to the Creative Commons license, and indicate if changes were made.

\section{References}

1. Stewart B, Wild CP et al (2014) World cancer report 2014

2. Senesse P, Bachmann P, Bensadoun RJ et al (2014) Clinical nutrition guidelines of the French Speaking Society of Clinical Nutrition and Metabolism (SFNEP): summary of recommendations for adults undergoing non-surgical anticancer treatment. Dig Liver Dis. https://doi.org/10.1016/j.dld.2014.01.160

3. De Pergola G, Silvestris F (2013) Obesity as a major risk factor for cancer. J Obes 2013:291546. https://doi.org/10.1155/2013/291546

4. Arce-Salinas C, Aguilar-Ponce JL, Villarreal-Garza C et al (2014) Overweight and obesity as poor prognostic factors in locally advanced breast cancer patients. Breast Cancer Res Treat 146:183-188. https://doi.org/10.1007/s10549-014-2977-8

5. Herlevic VC, Mowad R, Miller JK et al (2015) Breast cancer outcomes in a population with high prevalence of obesity. J Surg Res 198:371-376. https://doi.org/10.1016/j.jss.2015.03.088

6. von Drygalski A, Tran TB, Messer K et al (2011) Obesity is an independent predictor of poor survival in metastatic breast cancer: retrospective analysis of a patient cohort whose treatment included high-dose chemotherapy and autologous stem cell support. Int $\mathbf{J}$ Breast Cancer 2011:1-8. https://doi.org/10.4061/2011/523276

7. Chan DSM, Vieira AR, Aune D et al (2014) Body mass index and survival in women with breast cancer-systematic literature 
review and meta-analysis of 82 follow-up studies. Ann Oncol 25:1901-1914. https://doi.org/10.1093/annonc/mdu042

8. Cecchini RS, Swain SM, Costantino JP et al (2016) Body mass index at diagnosis and breast cancer survival prognosis in clinical trial populations from NRG Oncology/NSABP B-30, B-31, B-34, and B-38. Cancer Epidemiol Prev Biomark 25:51-59. https://doi. org/10.1158/1055-9965.EPI-15-0334-T

9. Gennari A, Amadori D, Scarpi E et al (2016) Impact of body mass index (BMI) on the prognosis of high-risk early breast cancer (EBC) patients treated with adjuvant chemotherapy. Breast Cancer Res Treat 159:79-86. https://doi.org/10.1007/s10549-0163923-8

10. Prado CMM, Lieffers JR, McCargar LJ et al (2008) Prevalence and clinical implications of sarcopenic obesity in patients with solid tumours of the respiratory and gastrointestinal tracts: a population-based study. Lancet Oncol 9:629-635. https://doi.org/ 10.1016/S1470-2045(08)70153-0

11. Mitsiopoulos N, Baumgartner RN, Heymsfield SB et al (1998) Cadaver validation of skeletal muscle measurement by magnetic resonance imaging and computerized tomography. J Appl Physiol Bethesda Md 85:115-122

12. Rutten IJ, Dijk DP, Kruitwagen RF et al (2016) Loss of skeletal muscle during neoadjuvant chemotherapy is related to decreased survival in ovarian cancer patients. J Cachex Sarcopenia Muscle 7:458-466. https://doi.org/10.1002/jcsm.12107

13. Anandavadivelan P, Brismar TB, Nilsson M et al (2016) Sarcopenic obesity: a probable risk factor for dose limiting toxicity during neoadjuvant chemotherapy in oesophageal cancer patients. Clin Nutr 35:724-730. https://doi.org/10.1016/j.clnu.2015.05.011

14. Antoun S, Borget I, Lanoy E (2013) Impact of sarcopenia on the prognosis and treatment toxicities in patients diagnosed with cancer. Curr Opin Support Palliat Care 7:383-389. https://doi.org/10.1097/ SPC.0000000000000011

15. Lodewick TM, van Nijnatten TJA, van Dam RM et al (2015) Are sarcopenia, obesity and sarcopenic obesity predictive of outcome in patients with colorectal liver metastases? HPB 17:438-446. https:// doi.org/10.1111/hpb.12373

16. Martin L, Birdsell L, Macdonald N et al (2013) Cancer cachexia in the age of obesity: skeletal muscle depletion is a powerful prognostic factor, independent of body mass index. J Clin Oncol Off J Am Soc Clin Oncol 31:1539-1547. https://doi.org/10.1200/JCO.2012. 45.2722

17. Shachar SS, Williams GR, Muss HB, Nishijima TF (2016) Prognostic value of sarcopenia in adults with solid tumours: a meta-analysis and systematic review. Eur J Cancer Oxf Engl 57: 58-67. https://doi.org/10.1016/j.ejca.2015.12.030

18. Fabbro ED, Parsons H, Warneke CL et al (2012) The relationship between body composition and response to neoadjuvant chemotherapy in women with operable breast cancer. Oncologist 17: 1240-1245. https://doi.org/10.1634/theoncologist.2012-0169

19. Villaseñor A, Ballard-Barbash R, Baumgartner K et al (2012) Prevalence and prognostic effect of sarcopenia in breast cancer survivors: the HEAL Study. J Cancer Surviv 6:398-406

20. Wong AL, Seng KY, Ong EM et al (2014) Body fat composition impacts the hematologic toxicities and pharmacokinetics of doxorubicin in Asian breast cancer patients. Breast Cancer Res Treat 144:143-152. https://doi.org/10.1007/s10549-014-2843-8

21. Iwase T, Sangai T, Nagashima $T$ et al (2016) Impact of body fat distribution on neoadjuvant chemotherapy outcomes in advanced breast cancer patients. Cancer Med 5:41-48. https://doi.org/10. 1002/cam4.571
22. Antoun S, Bayar A, Ileana E et al (2015) High subcutaneous adipose tissue predicts the prognosis in metastatic castrationresistant prostate cancer patients in post chemotherapy setting. Eur J Cancer Oxf Engl 51:2570-2577. https://doi.org/10.1016/j. ejca.2015.07.042

23. Cutuli B, Giard-Lefevre S, Antoine M et al (2012) Cancer du sein infiltrant non métastatique - questions d'actualités (synthèse) 82 . www.e-cancer.fr/content/download/95914/1021156/file/ RECOSEININFILT12.PDF

24. Shen W, Punyanitya M, Wang Z et al (2004) Total body skeletal muscle and adipose tissue volumes: estimation from a single $a b-$ dominal cross-sectional image. J Appl Physiol Bethesda Md 97: 2333-2338. https://doi.org/10.1152/japplphysiol.00744.2004

25. Shachar SS, Deal AM, Weinberg M et al (2016) Skeletal muscle measures as predictors of toxicity, hospitalization, and survival in patients with metastatic breast cancer receiving taxane based chemotherapy. Clin Cancer Res Clincanres. https://doi.org/10.1158/ 1078-0432.CCR-16-0940

26. Guiu B, Petit JM, Bonnetain F et al (2010) Visceral fat area is an independent predictive biomarker of outcome after first-line bevacizumab-based treatment in metastatic colorectal cancer. Gut 59:341-347. https://doi.org/10.1136/gut.2009.188946

27. Moon H-G, Ju Y-T, Jeong C-Y et al (2008) Visceral obesity may affect oncologic outcome in patients with colorectal cancer. Ann Surg Oncol 15:1918-1922

28. Yip C, Dinkel C, Mahajan A et al (2015) Imaging body composition in cancer patients: visceral obesity, sarcopenia and sarcopenic obesity may impact on clinical outcome. Insights Imaging 6:489-497. https://oi.org/10.1007/s13244-015-0414-0

29. Sottier D, Petit J-M, Guiu S et al (2013) Quantification of the visceral and subcutaneous fat by computed tomography: interobserver correlation of a single slice technique. Diagn Interv Imaging 94: 879-884

30. Cruz-Jentoft AJ, Baeyens JP, Bauer JM et al (2010) Sarcopenia: European consensus on definition and diagnosis report of the European working group on sarcopenia in older people. Age Ageing 39:412-423. https://doi.org/10.1093/ageing/afq034

31. Fielding R, Kirn D, Koochek A et al (2016) PT02.5: impact of a structured physical activity program and nutritional supplementation on regional body composition: results from the Vitality, Independence, and Vigor in the Elderly 2 Study (VIVE2). Clin Nutr 35:S25. https://doi.org/10.1016/S0261-5614(16)30294-1

32. Janssen I, Heymsfield SB, Ross R (2002) Low relative skeletal muscle mass (sarcopenia) in older persons is associated with functional impairment and physical disability. J Am Geriatr Soc 50: 889-896

33. van Dijk DPJ, Bakens MJAM, Coolsen MME et al (2016) Low skeletal muscle radiation attenuation and visceral adiposity are associated with overall survival and surgical site infections in patients with pancreatic cancer. J Cachexia Sarcopenia Muscle. https://doi. org/10.1002/jcsm. 12155

34. Kim TY, Kim MY, Sohn JH et al (2014) Sarcopenia as a useful predictor for long-term mortality in cirrhotic patients with ascites. $\mathrm{J}$ Korean Med Sci 29:1253-1259. https://doi.org/10.3346/jkms. 2014.29.9.1253

35. Matsuzawa Y (2002) New criteria for "obesity disease" in Japan: the Examination Committee of Criteria for "Obesity Disease" in Japan, Japan Society for the Study of Obesity. Circ J Off J Jpn Circ Soc 66:987-992

36. Xiao J, Mazurak VC, Olobatuyi TA et al (2016) Visceral adiposity and cancer survival: a review of imaging studies. Eur J Cancer Care (Engl). https://doi.org/10.1111/ecc.12611 